\title{
Adrenergic mechanisms in control of plasma lipid concentrations
}

\author{
J L DAY, J METCALFE, C N SIMPSON
}

\begin{abstract}
The mechanisms of the changes in plasma lipid concentrations observed after beta-blockade were examined in 53 patients with hypertension receiving treatment with atenolol, metoprolol, propranolol, and oxprenolol in a randomised cross-over trial.

Significant increases in mean plasma total and verylow-density lipoprotein (VLDL) triglyceride and reductions in high-density lipoprotein (HDL) cholesterol and free fatty acid concentrations were observed with all four drugs, the increase in plasma triglyceride concentration being greatest after propranolol and oxprenolol. No significant changes were observed in total or LDL cholesterol concentrations, but HDL:LDL ratios and HDL cholesterol as a proportion of total cholesterol fell significantly. Thus plasma lipid concentrations should be monitored after three to six months of long-term treatment. Changes in triglyceride, HDL cholesterol and free fatty acid concentrations were associated with a highly significant reduction in clearance of soya oil (Intralipid) in 25 patients studied but were unrelated to changes in blood pressure. The fall in HDL cholesterol and rise in free fatty acid concentrations were significantly less in those with initially reduced HDL cholesterol or raised free fatty acid concentrations respectively.

It is proposed that unopposed alpha stimulation inhibits lipoprotein lipase with a subsequent rise in plasma triglyceride and fall in HDL cholesterol concentration. Analysis of the relation between pretreatment concentrations and subsequent changes suggests that excessive alpha stimulation may impair production of HDL cholesterol in those with low HDL cholesterol concentrations before treatment. Subtle catecholamine-mediated
\end{abstract}

Ipswich Hospital, Heath Road Wing, Ipswich, Suffolk

J L DAY, MD, FRCP, consultant physician

J METCALFE, BSC, research assistant

C N SIMPSON, $M B, M R C P$, registrar changes in plasma lipid concentrations might provide a mechanism for the relation between stress and the development of cardiovascular events.

\section{Introduction}

Treatment with beta-adrenergic antagonists has been associated with an increase in plasma triglyceride and a fall in highdensity lipoprotein (HDL) cholesterol concentrations. ${ }^{1-4}$ These observations provide preliminary evidence that adrenergic mechanisms may play an important part in controlling plasma lipid concentrations. Specific action of the beta-blocking drugs rather than a secondary response to their hypotensive action is suggested by the failure to detect similar changes in patients treated with labetalol ${ }^{5}$ and a fall in triglyceride concentration in subjects treated with prazosin. ${ }^{2}$ The hypertriglyceridaemia observed after thiazide treatment probably has a different mechanism. ${ }^{6}$

We undertook a study to elucidate the mechanism of the changes in plasma lipid concentrations after beta-adrenergic blockade. We examined the response to agents with differing degrees of selectivity and intrinsic sympathomimetic activity, the interrelation between changes in plasma total and very-low density lipoprotein (VLDL) triglyceride and HDL and lowdensity lipoprotein (LDL) cholesterol concentrations and change in lipoprotein lipase function, and the relation between the degree of response and pretreatment characteristics.

\section{Patients and methods}

From one group practice we selected 53 previously untreated men and women with hypertension on the basis of at least three recordings of diastolic blood pressure in excess of $90 \mathrm{~mm} \mathrm{Hg}$ for entry into a double-blind randomised cross-over study. Patients were treated for 12 months with four drugs given for three months each: atenolol (100 $\mathrm{mg})$, metoprolol (100 mg twice daily), oxprenolol ( $80 \mathrm{mg}$ twice daily), and propranolol ( $80 \mathrm{mg}$ twice daily). The drugs were given in random order, and matched active and dummy tablets were provided.

Plasma was obtained after an overnight fast at 900 am after the patients had been lying down for half an hour and measurement made of plasma total and VLDL triglyceride; total, LDL, and HDL 
cholesterol; and free fatty acid concentrations. Blood pressure was measured with a random zero sphygmomanometer by an independent observer. Estimations were performed before treatment and at the end of each three-month period of treatment. Subjects over $20 \%$ ideal body weight or with angina, claudication, obstructive airways disease, known carbohydrate intolerance, or other endocrine, renal, hepatic, or gastrointestinal disease were excluded. Informed consent was obta'ned from all subjects.

Twenty-five of the subjects underwent an Intralipid (soya oil) clearance test before and after three months' treatment with one of the four beta-blockers according to the method of Lewis et al. ${ }^{7}$ Intralipid was administered at a dose of $1 \mathrm{ml} / \mathrm{kg}$ body weight. The fractional rate of removal of triglyceride $\left(\% / \mathrm{min} ; \mathrm{k}_{2}\right)$ was calculated from sequential analysis of plasma emulsion concentrations by nephelometry. Total triglyceride and cholesterol concentrations were measured by Boehringer enzymatic methods. HDL cholesterol concentration was estimated using heparin manganese precipitation. ${ }^{8}$ VLDL triglyceride and LDL cholesterol concentrations were measured by the dual precipitation method. ${ }^{9}$

Statistical analysis-Paired $t$ tests were performed to obtain values for differences in all the variables before and after each treatment period at three, six, nine, and 12 months respectively. Covariant analysis was performed to determine the correlation between changes in the variables and also the relation between the magnitude of changes after treatment and the initial values of the variables.

\section{Results}

Table I shows the mean values of the lipid concentrations at various time intervals after the start of treatment. In the 53 subjects as a whole, regardless of the drug taken, there was a highly significant fall in plasma HDL cholesterol concentration from the pretreatment mean value of $1.32 \pm S E M 0.05$ to $1.14 \pm 0.04 \mathrm{mmol} / 1(51.0 \pm 1.9$ to $44.1 \pm$ $1.5 \mathrm{mg} / 100 \mathrm{ml}$ ) after the first treatment period with no further significant fall during the study, the mean value at the end of the 12 months being $1.13 \pm 0.05 \mathrm{mmol} / 1(43.7 \pm 1.9 \mathrm{mg} / 100 \mathrm{ml})$. Coincidentally, total plasma triglyceride concentrations rose significantly from a pretreatment mean of $1.49+0.09$ to $1.79+0.17 \mathrm{mmol} / 1(131.9+8.0$ to $158 \cdot 5 \pm 15 \cdot 1 \mathrm{mg} / 100 \mathrm{ml})$ after three months and $2 \cdot 16 \pm 0 \cdot 19 \mathrm{mmol} / \mathrm{l}$ $(191 \cdot 3+16.8 \mathrm{mg} / 100 \mathrm{ml})$ at the end of the 12 months. Changes in VLDL triglyceride concentrations paralleled those in total triglyceride concentrations. Mean total and LDL cholesterol concentrations did not change throughout the study. Concentrations of free fatty acid fel throughout the 12 months from a mean of $0.84 \pm 0.04 \mathrm{mmol}(\mathrm{mEq}) / 1$ to $0.46 \pm 0.03 \mathrm{mmol} / 1$

We compared the lipid concentrations at the end of each period of drug treatment not only with the initial, pretreatment concentrations but also with the concentrations before that particular treatment period. Plasma triglyceride concentrations had increased significantly at the end of treatment with all four drugs compared with the initial pretreatment values (table II). Mean values were higher at the end of treatment with propranolol $(2 \cdot 33 \pm 0.26 \mathrm{mmol} / 1(206 \cdot 3 \pm 23 \cdot 0 \mathrm{mg} / 100$ $\mathrm{ml})$ ) but were not significantly different from those at the end of treatment with the three other agents.

When plasma triglyceride concentrations before and after each treatment period were compared they were significantly higher after treatment with only oxprenolol and propranolol. When mean total triglyceride concentrations at the end of each treatment period were pooled those after oxprenolol and propranolol were significantly highe $(2 \cdot 05+0 \cdot 18 \mathrm{mmol} / \mathrm{l}(181.5+15.9 \mathrm{mg} / 100 \mathrm{ml}))$ than those after atenolol and metoprolol $(1.86 \pm 0.18 \mathrm{mmol} / \mathrm{l}(164.7+15.9 \mathrm{mg} / 100 \mathrm{ml}))(\mathrm{p}<$ 0.025). Plasma HDL cholesterol concentrations were significantly lower after treatment with each drug than initially, and all these differences were significant. Although the greatest fall in HDL

TABLE I-Mean $\pm S E M$ fasting plasma lipid concentrations before and during beta-adrenergic blockade $(n=53)$

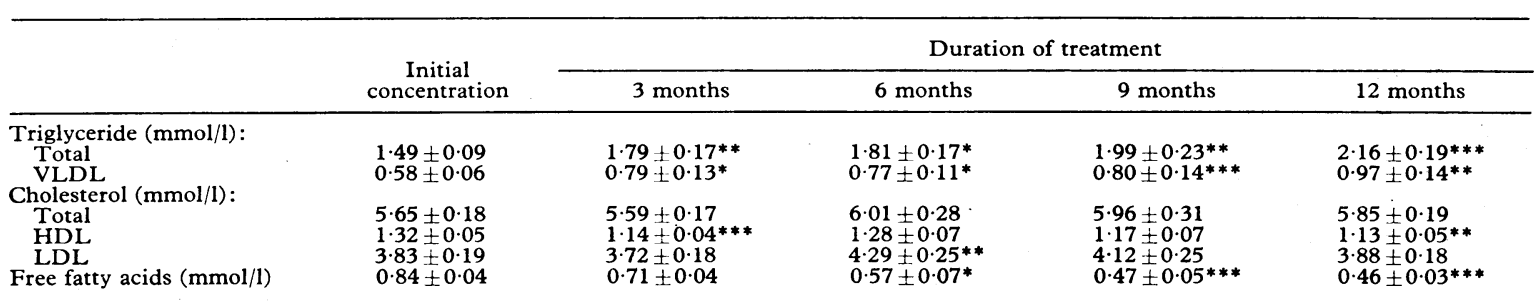

Significance of difference from initial concentration: ${ }^{*} \mathrm{p}<0.05 \quad * * \mathrm{p}<0.01 * * * \mathrm{p}<0.001$.

Conversion: SI to traditional units-Triglyceride: $1 \mathrm{mmol} / 1 \approx 88.6 \mathrm{mg} / 100 \mathrm{ml}$. Cholesterol: $1 \mathrm{mmol} / 1 \approx 38.7 \mathrm{mg} / 100 \mathrm{ml}$. Free fatty acids: $1 \mathrm{mmol} / 1=$ $1 \mathrm{mEq} / \mathrm{l}$.

TABLE II-Mean $\pm S E M$ plasma lipid concentrations before and after treatment with each of the four beta-blocking drugs

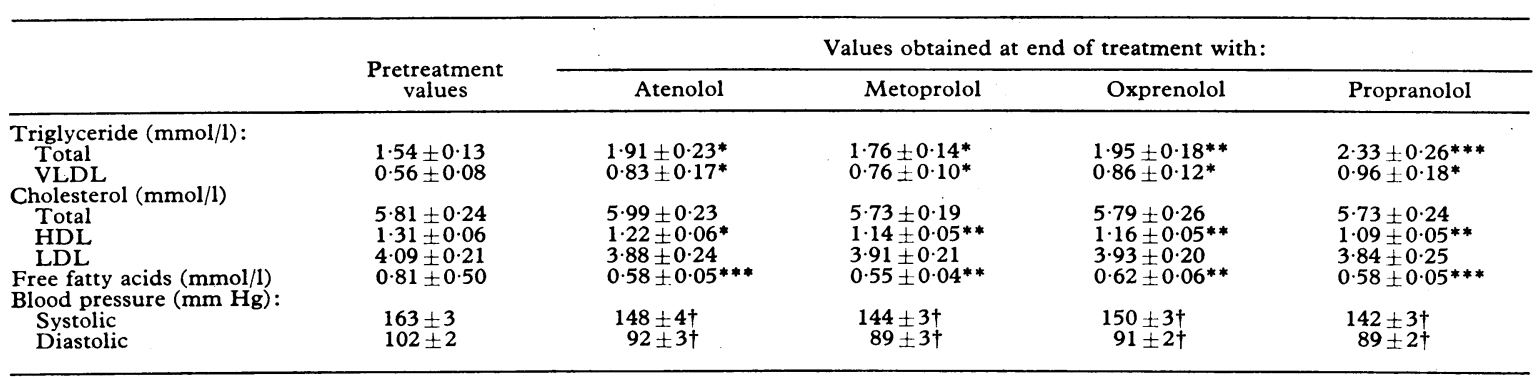

Significance of difference from initial concentration: ${ }^{*} \mathrm{p}<0.05^{* *} \mathrm{p}<0.01{ }^{* * *} \mathrm{p}<0.001$.
†All values significantly different from initial value, but no significant differences between means at end of each treatment period. Conversion: SI to traditional units-Triglyceride: $1 \mathrm{mmol} / 1 \approx 88.6 \mathrm{mg} / 100 \mathrm{ml}$. Cholesterol: $1 \mathrm{mmol} / 1 \approx 38.7 \mathrm{mg} / 100 \mathrm{ml}$. Free fatty acids: $1 \mathrm{mmol} / 1$
$=1 \mathrm{mEq} / 1$.

TABLE III-Mean \pm SEM lipid concentrations in 25 subjects who underwent tests of Intralipid clearance before and after three months' treatment

\begin{tabular}{|c|c|c|c|c|c|c|c|}
\hline & \multicolumn{2}{|c|}{ Triglyceride $(\mathrm{mmol} / \mathrm{l})$} & \multicolumn{2}{|c|}{ Cholesterol $(\mathrm{mmol} / \mathrm{l})$} & \multirow{2}{*}{$\begin{array}{l}\text { Free fatty acids } \\
\quad(\mathrm{mmol} / \mathrm{l})\end{array}$} & \multirow{2}{*}{$\underset{(\% / \mathrm{min})}{k_{2}}$} & \multirow{2}{*}{$\underset{(\min )}{\text { Half life }}$} \\
\hline & Total & VLDL & Total & HDL & & & \\
\hline $\begin{array}{l}\text { Initial } \\
\text { After } 3 \text { months }\end{array}$ & $\begin{array}{l}1 \cdot 76 \pm 0 \cdot 20 \\
2 \cdot 11 \pm 0 \cdot 21^{*}\end{array}$ & $\begin{array}{l}0.69 \pm 0 \cdot 11 \\
0.82 \pm 0 \cdot 12\end{array}$ & $\begin{array}{l}5 \cdot 68 \pm 0 \cdot 28 \\
6 \cdot 34 \pm 0.31^{* *}\end{array}$ & $\begin{array}{l}1 \cdot 12 \pm 0.47 \\
1 \cdot 12 \pm 0 \cdot 05\end{array}$ & $\begin{array}{l}0.72 \pm 0.05 \\
0.71 \pm 0.06\end{array}$ & $\begin{array}{l}2.07 \pm 0.15 \\
1.69 \pm 0.14^{* *}\end{array}$ & $\begin{array}{l}16.5 \pm 1 \cdot 6 \\
21.2 \pm 1.9 *\end{array}$ \\
\hline
\end{tabular}

Significance of difference from pretreatment value: ${ }^{*} \mathrm{p}<0.05 \quad * * \mathrm{p}<0.01$.
Conversion: SI to traditional units - Triglyceride: $1 \mathrm{mmol} / 1 \approx 88 \cdot 6 \mathrm{mg} / 100 \mathrm{ml}$. Cholesterol: $1 \mathrm{mmol} / 1 \approx 38 \cdot 7 \mathrm{mg} / 100 \mathrm{ml}$. Free fatty acids: $1 \mathrm{mmol} / 1=1 \mathrm{mEq} / \mathrm{l}$. 
cholesterol concentration was observed at the end of treatment with propranolol and the least after treatment with atenolol, the difference between these means did not achieve significance at the $95 \%$ level $(p<0.01$; see table II). There was no significant difference in plasma total or LDL cholesterol concentrations at the end of the treatment periods with any of the drugs compared with the initial value. The reduction in blood pressure was similar with all four drugs.

The figure shows the rate of disappearance of Intralipid in the 25 subjects in whom tests of Intralipid clearance were performed before and after three months' treatment. In these patients there was a significant fall in $\mathrm{k}_{2}$ and significant prolongation of half life (table III). Pretreatment plasma lipid values did not differ significantly from those in the parent group of all 53 patients.

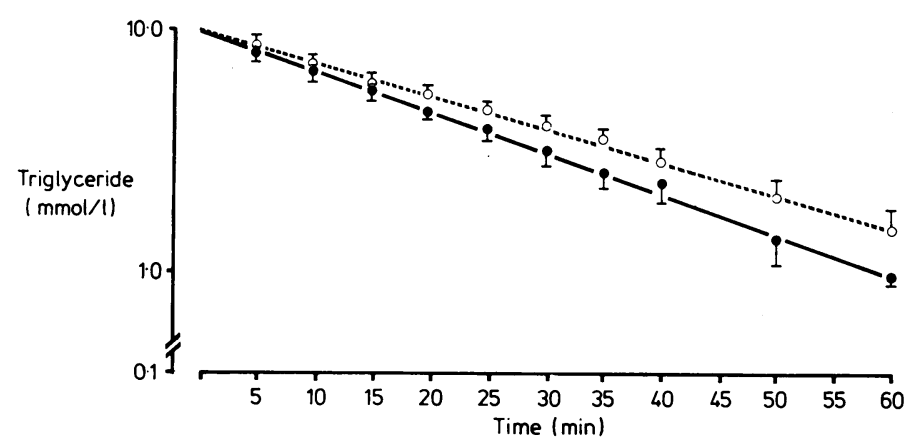

Triglyceride concentrations after injection of Intralipid at time 0. $=$ concentrations before, and $O-. .-O=$ concentrations after, three months' treatment with a beta-blocker.

Conversion: SI to traditional units-Triglyceride: $1 \mathrm{mmol} / 1 \approx 88.6 \mathrm{mg} / 100$ $\mathrm{ml}$.

Results of covariant analysis-Significant inverse correlations were obtained in all 53 patients between initial HDL cholesterol concentrations and initial triglyceride concentrations $(r=-0.45)$ and initial weight $(r=-0.59)$. The change in HDL cholesterol concentration correlated significantly but positively with the initial HDL cholesterol concentration and the initial concentration of free fatty acids-that is, those with the lowest initial concentration showed the least change $(r=0.45$ and 0.45 respectively). The change in concentration of free fatty acids correlated positively with the initial concentration $(r=$ $0.66)$. The slope of Intralipid clearance $\left(k_{2}\right)$ correlated with the difference in mean blood pressure $(r=0.54)$, but there were no significant changes between changes in mean blood pressure and changes in any of the individual lipid concentrations.

\section{Discussion}

We have confirmed previous observations of a rise in plasma triglyceride concentration and a fall in HDL cholesterol concentration after beta-adrenergic blockade. ${ }^{1-4}$ The additional information obtained in this study, however, appears to clarify the mechanism of these changes. Although the rise in triglyceride concentrations was rather greater when patients were given propranolol than when they received atenolol, metoprolol, or oxprenolol, significant increases were observed with all four drugs. When results of treatment with the more cardioselective drugs (atenolol and metoprolol) were pooled and compared with those of the less cardioselective (oxprenolol and propranolol) the increases in total and VLDL triglyceride concentrations were significantly lower with the more selective drugs. In a previous study propranolol appeared to be associated with a greater rise in triglyceride concentration than atenolol. ${ }^{1}$ Thus there are probably significant differences between drugs in these respects. It would appear that the more complete the betaadrenergic blockade with the less selective drugs the greater the change in plasma triglyceride concentration.

In this study no relation between changes in blood pressure and individual plasma lipid concentrations was observed, and although the rate of disappearance of Intralipid was correlated with a fall in blood pressure, these results suggest that the changes in plasma lipid concentrations represent a specific action of adrenergic antagonists rather than a secondary manifestation of their hypotensive effect. The failure to observe any significant changes in lipid concentration in patients treated with labetalol ${ }^{5}$ and a reduction in plasma triglyceride concentration after treatment with prazosin ${ }^{2} 9$ seem to confirm this.

The clinical importance of these changes is uncertain. Hypertriglyceridaemia is considered to be a less important risk factor than reduced HDL or raised LDL cholesterol concentrations. The changes in HDL cholesterol concentrations, however, must be viewed with some concern. Not only total concentrations but also (in view of constant or slightly rising LDL and total cholesterol concentrations) HDL:LDL ratios and HDL cholesterol as a proportion of total cholesterol declined. Since all have been considered to be important negative risk factors it seems prudent to check plasma lipid concentrations after a few months of betablockade in patients destined for long-term treatment.

The reduction of clearance of Intralipid, which is equivalent to fractional rate of removal of endogenous triglyceride, ${ }^{10-12}$ after adrenergic blockade was highly significant and in conjunction with a rise in total and VLDL triglyceride concentrations and a fall in plasma HDL cholesterol concentrations is of considerable interest. The formation of HDL cholesterol ${ }^{13-15}$ probably results from the catabolism of triglyceride-rich lipoproteins. Hence our findings of an inverse correlation between basal triglyceride and HDL cholesterol concentrations (confirming results of several other studies) ${ }^{16}{ }^{17}$ and the reciprocal change in triglyceride (increase) and HDL cholesterol concentrations (decrease) and a fall in Intralipid clearance during adrenergic blockade suggest that all these changes might be mediated through inhibition of liproprotein lipase activity.

The consistent decrease in free fatty acid concentrations during treatment argues against an increased rate of synthesis of triglyceride. We showed previously that these changes in triglyceride concentration cannot be related to changes in plasma insulin or glucose concentration. ${ }^{1}$ Inhibition of lipase could be achieved through either a direct inhibitory action of the adrenergic blocking agents themselves or secondary unopposed alphaadrenergic stimulation. During adrenergic blockade plasma catecholamine concentrations may be increased, ${ }^{18}$ and, in vitro, catecholamines appear to inactivate liproprotein lipase. ${ }^{19}$ It is unlikely that alteration of concentrations of $\mathrm{C}_{11}$ apoprotein, which activates the lipase, is responsible since Erkelens et $a^{12}$ suggested that these are not rate limiting. We also noted a significant inverse correlation between initial HDL cholesterol and free fatty acid concentrations and their changes during adrenergic blockade-that is, subjects with pre-existing low HDL cholesterol or free fatty acid concentrations showed the least change. This suggests the possibility that a mechanism similar to that during adrenergic blockade operates in some subjects before treatment. All these observations would be consistent with the hypothesis that it is predominantly alpha stimulation, unopposed during beta-blockade, that results in inhibition of lipase.

Further evidence that adrenergic inhibition of lipase may be an important mechanism in determining plasma lipid concentrations is provided by our (unpublished) observations, in a study of patients after myocardial infarction, of similar reciprocal changes between triglyceride and HDL cholesterol concentrations, which may be obviated by giving heparin.

The importance of a potential role for catecholamine in mediating plasma lipid concentration cannot be underestimated. Patients with pre-existing low HDL cholesterol and free fatty acid concentrations (in whom little change was observed during beta-blockade) might possibly be those exposed to excessive alpha-adrenergic tone. This might explain why subjects with type A behaviour patterns not only have an appreciably higher risk of coronary artery disease but also may have significantly higher cholesterol and triglyceride concentrations. ${ }^{20-22}$

We postulate, therefore, that alpha-adrenergic stimulation may have an important role in suppressing adipose tissue lipase with secondary reduction of plasma HDL cholesterol and raising of triglyceride concentrations. This could be an important 
mechanism linking stress and subtle alterations of lipid concentrations.

This study was carried out in collaboration with Drs F Wells, R Mercer, and D Mukerji, Orchard Street Health Centre, Ipswich, Suffolk, who provided all the patients.

We are grateful for the financial support provided for this study by an East Anglian Regional Health Authority research grant and grants from ICI and Stuart/Geigy Pharmaceuticals. We thank Miss C Gibbons for preparing the manuscript, and $\mathrm{Mrs} \mathrm{H}$ Humphries for technical help.

\section{References}

${ }^{1}$ Day JL, Simpson N, Metcalfe J, Page RL. Metabolic consequences of atenolol and propranolol in treatment of hypertension. $\mathrm{Br}$ Med $\mathcal{F}$ $1979 ; \mathrm{i}: 77-80$.

${ }^{2}$ Leren P, Foss PO, Helgeland A, Hjermann I, Holme I, Lund-Larsen PG. Effect of propranolol and prazosin on blood lipids. Lancet 1980;ii:4-6.

${ }^{3}$ Shaw J, England JDF, Hua ASP. Beta-blockers and plasma triglycerides. Br Med f 1978; ; :986.

${ }^{4}$ Lehtonen A, Viikan J. Long term effects of sotalol on plasma lipids. Clin Sci $1979 ; 57: 405-7 s$.

5 McGonigle RJS, Williams L, Murphy MJ, Parsans V. Labetalol and lipids. Lancet 1981 ; : 163.

${ }^{6}$ Ames RP, Hill P. Increase in serum lipids during treatment of hypertension with chlorthalidone. Lancet 1976; i:721-3.

${ }^{7}$ Lewis B, Boberg J, Mancini M, Carlson LA. Determination of the intravenous fat tolerance test with intralipid by nephelometry. Atherosclerosis $1972 ; 15: 83-6$.

${ }^{8}$ Burstein M, Samaille J. Sur un dosage rapide du cholesterol lie aux et aux $\beta$-lipoproteines du serum. Clin Chim Acta 1960;5:609.

9 Wilson DE, Spiger MJ. A dual precipitation method for quantitative plasma lipoprotein measurement without ultracentrifugation. $\mathcal{f} L a b$ Clin Med $1973 ; 82: 473-82$.
10 Hallberg D. Studies on the elimination of exogenous lipids from the blood stream. The kinetics of the elimination of a fat emulsion by a constant infusion technique in man. Acta Physiol Scand 1965;64:306-13.

11 Boberg J, Carlson LA, Hallberg D. Application of a new intravenous fat tolerance test in the study of hypertriglyceridaemia in man. Fournal of Atherosclerosis Research 1969;9:159-69.

12 Erkelens DW, Brunzell JD, Bierman EL. Availability of apolipoprotein CII in relation to the maximal removal capacity of infused triglyceride emulsion in man. Metabolism 1979;28:495-501.

13 Eisenberg S, Patsch JR, Olivecrona T, Gotto AM. Effects of lipolysis on human lipid density lipoproteins (HDL). Circulation 1978;58, suppl: abstract 47.

${ }^{14}$ Patsch JR, Gotto AM, Olivecrona T, Eisenberg S. Formation of high density lipoprotein-like particles during lipolysis of very low density lipoproteins in vitro. Proc Natl Acad Sci USA 1978;75:4519-23.

15 Tall AR, Small DM. Plasma high density lipoproteins. N Englf Med 1978; 299:1232-6.

16 Myers LH, Phillips NR, Havel RJ. Mathematical evaluation of methods for estimation of the concentration of the major lipid components of human serum lipoproteins. F Lab Clin Med 1976;88:491-505.

17 Schonfeld G, Bailey A, Steelman R. Plasma apolipoproteins, A-I and A-II levels in hyperlipidemia. Lipids 1978;13:951-9.

${ }^{18}$ Rahn KH, Gierlichs W, Planz G, Planz R, Schols M, Stephany W. Studies on the effects of propranolol on plasma catecholamine levels in patients with essential hypertension. Eur $\mathcal{F}$ Clin Invest 1978;8:143-8.

19 Ashby P, Parkin SM, Walker K, Bennett DP, Robinson DS. Hormonal control of adipose tissue lipoprotein lipase activity. INSERM Symposia $1980 ; 87: 149-60$.

${ }^{20}$ Rosenman RH, Brand RJ, Jenkins CD, Friedman H, Strauss R, Warm K. Coronary heart disease in the Western Collaboration Group Study. Final follow up experience of eight and a half years. $\mathcal{F} A M A 1975 ; \mathbf{2 3 3}$ : 872-7.

${ }^{21}$ Friedman $\mathrm{H}$, Rosenman RH. Association of specific overt behavior pattern with blood and cardiovascular findings. $\mathcal{F} A M A$ 1959;169:1286-96.

22 Friedman $H$, Rosenman RH, Byers SO. Serum lipids and conjugated circulation after fat ingestion in men exhibiting type A behaviour pattern. Circulation $1964 ; 29: 874-86$.

(Accepted 20 fanuary 1982)

\title{
Blood pressure and heart rate in patients with ischaemic heart disease receiving nifedipine and propranolol
}

\author{
LOUISE HARRIS, HENRY J DARGIE, PETER G LYNCH, CHRISTOPHER J BULPITT, \\ DENNIS M KRIKLER
}

\begin{abstract}
A randomised controlled crossover trial was performed to assess the anti-anginal effects of nifedipine and propranolol separately and together. The effects of these treatments on blood pressure and heart rate were assessed at rest and after the cold pressor and mental arithmetic tests. Nifedipine and propranolol together produced the greatest reduction in supine and erect systolic and diastolic blood pressures. Propranolol (480 mg daily) lowered resting systolic/diastolic blood pressures by $7 / 6 \mathrm{~mm} \mathrm{Hg}$ and nifedipine $(60 \mathrm{mg}$ daily) lowered it by $10 / 8 \mathrm{~mm} \mathrm{Hg}$, while in the erect position the
\end{abstract}

Division of Cardiovascular Disease, Royal Postgraduate Medical School, Hammersmith Hospital, London W12 0HS

LOUISE HARRIS, MB, MRCP, research fellow and honorary registrar

HENRY J DARGIE, MB, MRCP, honorary senior registrar (now consultant cardiologist, Western Infirmary, Glasgow)

PETER G LYNCH, MB, MRACP, research fellow and honorary registrar (present address: Prince Henry Hospital, Melbourne, Australia)

CHRISTOPHER J BULPITT, MD, MRCP, honorary senior lecturer, clinical pharmacology

DENNIS M KRIKLER, MD, FRCP, consultant cardiologist hypotensive effect of these agents averaged $9 / 8 \mathrm{~mm} \mathrm{Hg}$. During the cold pressor test propranolol lowered the maximum pressure by an average of $11 / 6 \mathrm{~mm} \mathrm{Hg}$ and nifedipine by $19 / 10 \mathrm{~mm} \mathrm{Hg}$. For the mental arithmetic test, the results were $7 / 2 \mathrm{~mm} \mathrm{Hg}$ and $16 / 7 \mathrm{~mm} \mathrm{Hg}$ respectively. Propranolol (480 mg daily) reduced supine and erect heart rate by 19 and 25 beats/minute respectively, while nifedipine did not alter heart rate significantly.

The favourable haemodynamic responses to nifedipine suggest that it may be of value in the management of hypertension.

\section{Introduction}

Since the principal haemodynamic abnormality in essential hypertension is an increase in peripheral vascular resistance, there is a rationale for using drugs that lower peripheral vascular resistance by a direct action on arteriolar smooth muscle. Contraction of vascular smooth muscle depends on the influx of calcium ions across the cell membrane through the "slow channels."1 Drugs which selectively block such transport, the calcium antagonists, relax vascular smooth muscle with an effect not only on peripheral vessels but also on the large 